\title{
Bab V
}

\section{Tipe dan Gaya Kepemimpinan}

\author{
Ahmad Masruri, Guru MA Jam'iyyah Islamiyyah Tangerang Selatan Banten \\ ahmad.masruri17@mhs.uinjkt.ac.id
}

\section{A. Pendahuluan}

Seiring perkembangan zaman, kepemimpinan secara ilmiah mulai berkembang bersamaan dengan pertumbuhan manajemen ilmiah yang lebih dikenal dengan ilmu tentang memimpin. Hal ini terlihat dari banyaknya literatur yang mengkaji tentang kepemimpinan (leadership) dengan berbagai sudut pandang atau perspektifnya. ${ }^{1}$

Dalam peradaban manusia sekarang ini segala aspek kehidupan tidak lepas dari berorganisasi, karena pada kodratnya manusia merupakan makhluk sosial yang cenderung untuk selalu hidup bermasyarakat. Hal ini nampak baik di dalam kehidupan rumah tangga, organisasi kemasyarakatan, terlebih pada saat seseorang memasuki dunia kerja. Seseorang tersebut akan berinteraksi, dan masuk menjadi bagian dalam organisasi tempatnya bekerja. Organisasi adalah unit sosial yang dengan sengaja dikelola, terdiri atas dua orang atau lebih, yang berfungsi secara relative terus-menerus untuk mencapai satu sasaran atau serangkaian sasaran bersama (Robbins, 2006: 6).

\footnotetext{
1 Saihu, S. (2019). RINTISAN PERADABAN PROFETIK UMAT MANUSIA MELALUI PERISTIWA TURUNNYA ADAM AS KE-DUNIA. Mumtaz: Jurnal Studi Al-Quran dan Keislaman, 3(2), 268-279,

Saihu, S. (2019). Pendidikan Pluralisme Agama: Kajian tentang Integrasi Budaya dan Agama dalam Menyelesaikan Konflik Sosial Kontemporer. Jurnal Indo-Islamika, 9(1), 67-90,

Saihu, S. (2019). IMPLEMENTASI MANAJEMEN BALANCED SCORECARD DI PONDOK PESANTREN JAM'IYYAH ISLAMIYYAH TANGERANG SELATAN. Mumtaz: Jurnal Studi Al-Quran dan Keislaman, 3(1), 1-22.

Saihu, S. (2019). KOMUNIKASI PENDIDIK TERHADAP ANAK BERKEBUTUHAN KHUSUS DI SEKOLAH KHUSUS ASY-SYIFA LARANGAN. Andragogi: Jurnal Pendidikan Islam dan Manajemen Pendidikan Islam, 1(3), 418-440.

Saihu, S., \& Marsiti, M. (2019). PENDIDIKAN KARAKTER DALAM UPAYA MENANGKAL RADIKALISME DI SMA NEGERI 3 KOTA DEPOK, JAWA BARAT. Andragogi: Jurnal Pendidikan Islam dan Manajemen Pendidikan Islam, 1(1), 23-54.
} 
Guna mencapai tujuan maupun sasaran yang diinginkan dalam sebuah organisasi, maka sudah semestinya seorang pemimpin mengetahui tipe dan gaya seperti apa yang layak dipergunakan dalam memimpin bawahannya. ${ }^{2}$

\section{B. Temuan dan Pembahasan}

\section{Definisi Kepemimpinan}

Sebelum kita menjelaskan secara komprehensif mengenai macammacam tipe atau gaya kepemimpinan dalam pendidikan, sudah seharusnya kita mengetahui pengertian dari pemimpin dan kepemimpinan itu sendiri. Agar nantinya memudahkan kita dalam memahami berbagai tipe dan gaya kepemimpinan, maka dari itu pada bagian awal kita jelaskan terlebih dahulu mengenai pengertian kepemimpinan.

Kepemimpinan adalah proses dalam mengarahkan dan mempengaruhi para anggota dalam hal berbagai aktivitas yang harus dilakukan. Konsep kepemimpinan dan pemimpinan mempunyai kaitan yang erat sekali. Pemimpin berasal dari kata asing leader dan kepemimpinan berasal dari leadership. Pemimpin adalah seorang pribadi yang memiliki superioritas tertentu, sehingga dia memiliki kewibawaan dan kekuasaan untuk menggerakkan orang lain melakukan usaha bersama guna mencapai sasaran tertentu (Kartono, 2005: 148).

Menurut Sharma (2013: 310), kepemimpinan adalah proses dimana seseorang mempengaruhi orang lain untuk mencapai tujuan dan mengarahkan organisasi dengan cara yang membuatnya lebih kohesif dan koheren.

\footnotetext{
${ }^{2}$ Saihu, S. (2019). KONSEP MANUSIA DAN IMPLEMENTASINYA DALAM PERUMUSAN TUJUAN PENDIDIKAN ISLAM MENURUT MURTADHA MUTHAHHARI. Andragogi: Jurnal Pendidikan Islam dan Manajemen Pendidikan Islam, 1(2), 197-217.

Saihu, S., \& Rohman, B. (2019). PEMBENTUKAN KARAKTER MELALUI MODEL PENDIDIKAN TRANSFROMATIFE LEARNING PADA SANTRI DI PONDOK PESANTREN NURUL IKHLAS BALI. Edukasi Islami: Jurnal Pendidikan Islam, 8(02), 435-452.

Saihu, S., \& Taufik, T. (2019). PERLINDUNGAN HUKUM BAGI GURU. Al Amin: Jurnal Kajian Ilmu dan Budaya Islam, 2(2), 105-116.

Saihu, S. (2020). KONSEP PEMBAHARUAN PENDIDIKAN ISLAM MENURUT FAZLURRAHMAN. Andragogi: Jurnal Pendidikan Islam dan Manajemen Pendidikan Islam, 2(1), 82-95.
} 
Dari beberapa pengertian tersebut dapat disimpulkan bahwa kepemimpinan adalah proses dalam mengarahkan dan mempengaruhi anggota untuk mencapai tujuan dan membuatnya lebih kohesif dan koheren atau efektif. ${ }^{3}$

Pemimpin memiliki peran yang sangat besar dalam pencapaian tujuan pendidikan sebagaimana yang ada dalam teori manajemen. Suatu organisasi akan berhasil atau gagal sebagian besar ditentukan oleh kepemimpinan lembaga itu. Tipe kepemimpinan akan identik dengan gaya kepemimpinan seseorang melaksanakan suatu kepemimpinan.

\section{Tipe-tipe Kepemimpinan}

Berbagai gaya atau tipe kepemimpinan banyak kita jumpai dalam kehidupan sehari-hari, termasuk di sekolah. Walaupun pemimpin pendidikan khususnya sekolah atau madrasah formal adalah pemimpin yang diangkat secara langsung baik oleh pemerintah maupun yayasan, atau melalui pemilihan (Sutikno, 2009: 71).

\section{Tipe Autocratic}

Autokratik yang menurut Kamus Besar Bahasa Indonesia (2008) menggunakan kata autokrasi yang berarti kekuasaan yang tidak terbatas dalam artian bentuk pemerintahan dengan kekuasaan mutlak pada diri seseorang, kediktatoran. Istilah lain dari autokrasi adalah otoriter yang mana kita lebih mengenal kata otoriter daripada autokrasi itu sendiri. Otoriter yang berarti berkuasa sendiri, sewenang-wenang. Merupakan

\footnotetext{
${ }^{3}$ Saihu, S. (2020). ETIKA MENUNTUT ILMU MENURUT KITAB TA'LIM MUTA'ALIM. $A l$ Amin: Jurnal Kajian Ilmu dan Budaya Islam, 3(1), 99-112.

Saihu, Aziz, A., Mubin, F., \& Sarnoto, A. Z. (2020). Design of islamic education based on local wisdom (An analysis of social learning theories in forming character through ngejot tradition in bali). International Journal of Advanced Science and Technology, 29(6), 1278-1293.

Ronaldo, R., Zulfikar, A., Saihu, Ismail, \& Wekke, I. S. (2020). International relations of the asia pacific in the age of trump. Journal of Environmental Treatment Techniques, 8(1), 244-246.

Saihu, M. M., \& Aziz, A. (2020). Implementasi Metode Pendidikan Pluralisme Dalam Mata Pelajaran Pendidikan Agama Islam. Belajea; Jurnal Pendidikan Islam, 5(1), 131-150.
} 
bentuk pemerintahan dengan kekuasaan pada diri pemimpin itu sendiri dilakukan dengan sewenang-wenang. ${ }^{4}$

Menurut Dwiwibawa (2012: 14). Pemimpin yang bertipe otokrasi adalah tipe seorang pemimpin yang sombong. Seorang pemimpin tipe ini akan mencampuradukan antara kepentingan pribadi dan organisasi. Ia juga akan melakukan segala cara, yang penting tujuannya tercapai. Dalam menjalankan tugasnya, seorang autokrasi akan,

(a) Menuntut ketaatan penuh dari bawahan.

(b) Bersikap kaku dalam menegakkan disiplin, tidak ada kesempatan bagi bawahan untuk mengemukakan alasan atau argumen.

(c) Bernada keras dalam memberikan perintah atau intruksi.

(d) Jika bawahan melakukan kesalahan, pemimpin tipe ini cenderung menggunakan pendekatan punitif atau memberi hukuman, dan

(e) Selalu berprinsip menang-kalah, pemimpin harus menang dan bawahan harus kalah.

Pemimpin bertindak sebagai diktator, pemimpin adalah pengerak dan penguasa kelompok. Kewajiban bawahan atau anggota-anggotanya hanyalah mengikuti dan menjalankan, tidak boleh membantah ataupun mengajukan saran (Afifuddin, 2005: 33).

Dalam kepemimpinan otokratik ini terlihat bahwa dalam melaksanakan kepemimpinannya, pemimpin bertindak sebagai penguasa sehingga segala tindakan dan keputusan atas suatu masalah sesuai dengan kehendak pemimpin. Dalam tipe kepemimpinan yang seperti ini, setiap bawahan harus taat dan patuh dengan aturan dan kebijakan yang dibuat oleh pemimpinnya. ${ }^{5}$

\footnotetext{
${ }^{4}$ Saihu, M. (2019). Urgensi 'Urf dalam Tradisi Male dan Relevansinya dalam Dakwah Islam di Jembrana-Bali. Jurnal Bimas Islam, 12(1), 173-201.

Saihu, S. (2020). The Effect of Using Talking Stick Learning Model on Student Learning Outcomes in Islamic Primary School of Jamiatul Khair, Ciledug Tangerang. Tarbawi: Jurnal Keilmuan Manajemen Pendidikan, 6(01), 61-68.

Saihu, S. (2020). Pendidikan sosial yang terkandung dalam Surat At-Taubah Ayat 71-72. Edukasi Islami: Jurnal Pendidikan Islam, 9(01), 127-148.

5 Aziz, A., \& Saihu, S. (2019). Interpretasi Humanistik Kebahasaan: Upaya Kontekstualisasi Kaidah Bahasa Arab. Arabiyatuna: Jurnal Bahasa Arab, 3(2), 299-214
} 
2. Tipe Democratic

Dari kata "demokratis" ini tergambar bahwa apa yang akan kita putuskan dan laksanakan itu disepakati dan dilakukan bersama-sama. Tipe demokratis berlandaskan pada pemikiran bahwa aktifitas dalam organisasi akan dapat berjalan lancar dan dapat mencapai tujuan yang telah ditetapkan apabila berbagai masalah yang timbul diputuskan bersama antara pejabat yang memimpin maupun para pejabat yang dipimpin. Seorang pemimpin yang demokratis menyadari bahwa organisasi harus disusun sedemikian rupa sehingga mengambarkan secara jelas beragam tugas dan kegiatan yang harus dilaksanakan demi tercapainya tujuan organisasi (Suryosubroto, 2010: 290).

Menurut Dwiwibawa (2012: 17), pemimpin demokratik memperlakukan manusia dengan cara manusiawi. Ia mengakui dan menjunjung tinggi harkat dan martabat manusia. Seorang demokratik tidak memandang bahwa kebutuhan manusia hanya terbatas pada kebutuhan materi, namun ia menyadari bahwa masih ada kebutuhan lain yang harus dipenuhi seperti fisik, mental, sosial, dan spiritual.

Tipe demokratik ini merupakan tipe kepemimpinan yang banyak sekali disukai para bawahannya. Karena, segala macam pemikiran dan juga ide diputuskan secara bersama guna mencapai tujuan yang diinginkan. ${ }^{6}$

Saihu, S. (2019). PENDIDIKAN KARAKTER BERBASIS KEARIFAN LOKAL (STUDI DI JEMBRANA BALI). Edukasi Islami: Jurnal Pendidikan Islam, 8(01), 69-90.

Şahin, C. RELIGIA.

Saihu, S., \& Mailana, A. (2019). Teori pendidikan behavioristik pembentukan karakter masyarakat muslim dalam tradisi Ngejot di Bali. Ta'dibuna: Jurnal Pendidikan Islam, 8(2), 163176.

Mubin, F. KEADILAN DALAM GENDER: KAJIAN KEPEMIMPINAN WANITA DALAM ISLAM1,

6 Saihu, M. (2019). Merawat Pluralisme Merawat Indonesia (Potret Pendidikan Pluralisme Agama Di Jembrana-Bali). Deepublish.

Mubin, F. (2019). TAFSIR EMANSIPATORIS: PEMBUMIAN METODOLOGI TAFSIR PEMBEBASAN. Mumtaz: Jurnal Studi Al-Quran dan Keislaman, 3(1), 131-151.

Mubin, F. MODEL-MODEL PEMBELAJARAN BERBASIS MADRASAH DAN KEGIATAN LAIN YANG DIPERLUKAN DI DALAMNYA (FAKTOR PENDUKUNGNYA).

Saihu, S. (2018). PENDIDIKAN ISLAM MULTIKULTURALISME. Al Amin: Jurnal Kajian Ilmu dan Budaya Islam, 1(2), 170-187. 


\section{Tipe Laissez Faire}

Laissez faire (kendali bebas) merupakan kebalikan dari pemimpin otokrasi. Jika pemimpin otokratik selalu mendominasi organisasi maka pemimpin laissez faire ini memberi kekuasaan sepenuhnya kepada anggota atau bawahan. Bawahan dapat mengembangkan sarannya sendiri, memecahkan masalahnya sendiri dan pengarahan tidak ada atau hanya sedikit (Afifuddin, 2005: 34).

Adapun sifat kepemimpinan laissez faire seolah-olah tidak tampak, sebab pada tipe ini seorang pemimpin memberikan kebebasan penuh kepada para anggotanya dalam melaksanakan tugasnya. Disini seorang pemimpin mempunyai kenyakinan bahwa dengan memberikan kebebasan yang seluas-luasnya terhadap bawahan maka semua usahanya akan cepat berhasil. Tingkat keberhasilan organisasi atau lembaga yang dipimpin dengan gaya laissez faire semata-mata disebabkan karena kesadaran dan dedikasi beberapa anggota kelompok dan bukan karena pengaruh dari pemimpinnya (Sutikno, 2009: 157).

Pemimpin tipe laissez faire biasanya menjadikan bawahan itu sebagai rekan kerja karena bersama-sama melaksanakan tugasnya sampai kepada tujuan yang diinginkan.

\section{Tipe Patternalistic}

Tipe kepemimpinan seperti ini biasa terdapat di lingkungan masyarakat desa yang masih bersifat tradisional dan agraris. Seorang pemimpin paternalistik memiliki gaya memimpin yang kebapakan, melindungi tapi juga menggurui. Dalam menjalankan tugasnya, seorang paternalistik selalu mengutamakan kepentingan bersama/kebersamaan. Ia selalu memperlakukan setiap orang dalam organisasinya sama, tidak ada yang lebih menonjol. Artinya seorang paternalistik berusaha memperlakukan semua orang dan semua satuan kerja yang terdapat ddalam organisasi seadil dan semerata mungkin (Dwiwibawa, 2012: 15) 
Karena paternalistik ini mempunyai arti sifat kebapaan, maka pemimpin tipe seperti ini cenderung mengayomi dan menjadikan bawahannya itu sebagai anaknya.

5. Tipe Karismatik

Dalam Kamus Besar Bahasa Indonesia (2008), yang dimaksud dengan karisma adalah keadaan atau bakat yang dihubungkan dengan kemampuan yang luar biasa dalam hal kepemimpinan seseorang untuk membangkitkan pemujaan dan rasa kagum dari masyarakat terhadap dirinya. Menurut Dwiwibawa (2012: 15), seorang pemimpin yang karismatik adalah pemimpin yang dikagumi oleh banyak pengikut meskipun mereka tidak dapat menjelaskan secara konkret mengapa ia mengaguminya.

Tipe kepemimpinan yang karismatik ini pada dasarnya merupakan tipe kepemimpinan yang didasarkan pada karisma seseorang. Biasanya karisma seseorang itu dapat mempengaruhi orang lain. Dengan karisma yang dimiliki seseorang, orang tersebut akan mampu mengarahkan bawahannya. Seorang pemimpin yang karismatik memiliki karakteristik khusus yaitu daya tariknya yang sangat memikat sehingga mampu memperoleh pengikut yang sangat besar dan para pengikutnya.

Kelima tipe kepemimpinan di atas dalam praktiknya saling isi mengisi atau saling menunjang secara bervariasi, yang disesuaikan dengan situasinya sehingga akan menghasilkan kepemimpinan yang efektif.

Tabel 1. Tipe Kepemimpinan dan Pendekatan

\begin{tabular}{|l|l|}
\hline \multicolumn{1}{|c|}{ Tipe Kepemimpinan } & Pendekatan \\
\hline Autocratic & Kekuasaan pada pemimpin \\
\hline Demokratic & Kekuasaan pada bawahan \\
\hline Laissez Faire & Kekuasaan pada bawahan \\
\hline
\end{tabular}




\begin{tabular}{|l|l|}
\hline Patternalistic & Kekuasaan pada pemimpin \\
\hline Kharismatik & Kekuasaan pada pemimpin \\
\hline
\end{tabular}

\section{Gaya Kepemimpinan}

Dalam Kamus Besar Bahasa Indonesia (2008), yang dimaksud dengan gaya yang berarti kesanggupan untuk berbuat dan sebagainya atau bisa juga diartikan dengan kekuatan. Dengan demikian gaya kepemimpinan bisa diartikan pola tingkah laku yang dirancang sedemikian rupa untuk mempengaruhi bawahannya agar dapat memaksimalkan kinerja yang dimiliki bawahannya sehingga kinerja organisasi dan tujuan organisasi dapat dimaksimalkan.

Seorang pemimpin harus menerapkan gaya kepemimpinan untuk mengelola bawahannya, karena seorang pemimpin akan sangat mempengaruhi keberhasilan organisasi dalam mencapai tujuannya (Guritno dan Waridin, 2005: 65). Menurut Tjiptono (2006: 161), gaya kepemimpinan adalah suatu cara yang digunakan pemimpin dalam berinteraksi dengan bawahannya. Sementara itu, pendapat lain menyebutkan bahwa gaya kepemimpinan adalah pola tingkah laku (kata-kata dan tindakan-tindakan) dari seorang pemimpin yang dirasakan oleh orang lain (Hersey, 2004: 29).

Dari beberapa pengertian di atas gaya kepemimpinan merupakan suatu pola tingkah laku baik dalam bentuk kata-kata maupun tindakan yang digunakan pemimpin dalam berinteraksi dengan bawahan.

\section{Gaya Persuasive}

Gaya pemimpin persuasif adalah gaya memimpin dengan menggunakan pendekatan yang mengubah perasaan, pikiran atau dengan kata lain melakukan ajakan atau bujukan (Sutrisno, 2010:242).

Dengan demikian gaya kepemimpinan persuasif adalah gaya memimpin dengan menggunakan pendekatan yang menggugah perasaaan, pikiran, atau dengan kata lain dengan melakukan ajakan atau bujukan. 


\section{Gaya Represif}

Dalam Kamus Besar Bahasa Indonesia (2008), yang dimaksud dengan represif adalah menekan, mengekang, menahan atau menindas. Dengan kata lain gaya kepemimpinan dengan cara memberi tekanan, mengekang, bahkan sampai menindas sehingga para bawahan merasa takut.

Menurut Sutrisno (2010: 242), gaya pemimpin represif adalah gaya kepemimpinan dengan cara memberikan tekanan-tekanan, ancaman-ancaman, sehingga bawahan merasa ketakutan.

Dengan kata lain gaya represif merupakan gaya kepemimpinan dengan cara memberikan tekanan-tekanan, ancaman-ancaman, sehingga bawahan merasa ketakutan yang bertujuan mengembalikan keserasian.

3. Gaya Partisipatif

Gaya pemimpin partisipatif adalah gaya kepemimpinan dengan cara memberikan kesempatan kepada bawahan untuk itu secara aktif baik menata, spiritual, fisik maupun material dalam kiprahnya dalam perusahaan (Sutrisno, 2010: 242).

Sedangkan menurut Hasibuan (2006: 205), kepemimpinan partisipatif yaitu jika seseorang pemimpin dalam melaksanakan kepemimpinannya dilakukan secara persuasif, menciptakan kerja sama yang serasi, menumbuhkan loyalitas dan partisipasi bawahannya. Pemimpin memotivasi para bawahan, agar mereka merasa ikut memiliki perusahaan, falsafah pemimpin, pemimpin adalah untuk bawahan, dan bawahan diminta untuk berpartisipasi dalam proses pengambilan keputusan dengan memberikan informasi, saran-saran dan pertimbangan. Pemimpin menerapkan sistem terbuka (open management). Informasi dan pembinaan kaderisasi mendapat perhatian serius.

Dengan demikian kepemimpinan partisipasif merupakan gaya kepemimpinan dengan menerapkan sistem terbuka dengan memberikan kesempatan kepada bawahan berperan aktif dalam menata baik memberikan informasi maupun saran-saran demi keserasian. 


\section{Gaya Inovatif}

Gaya pemimpin Inovatif adalah pemimpin yang selalu berusaha dengan keras untuk mewujudkan usaha-usaha pembaruan didalam segala bidang, baik bidang politik, ekonomi, sosial, budaya atau setiap produk terkait dengan kebutuhan manusia (Sutrisno, 2010: 244).

Dengan kata lain gaya pemimpin seperti ini selalu memiliki inovasi pembaharuan demi lancarnya suatu organisasi baik dalam hal pemecahan masalah maupun dalam hal menciptakan produk terkait kebutuhan manusia dan perkembangan zamannya.

5. Gaya Motivatif

Gaya pemimpin motivatif adalah pemimpin yang dapat menyampaikan informasi mengenai ide-idenya, program-program dan kebijakan-kebijakan kepada bawahan dengan baik. Komunikasi tersebut membuat segala ide bawahan-bawahan dan kebijakan dipahami oleh bawahan sehingga bawahan mau (Sutrisno, 2010: 245).

Motivasi juga bagian inti dari dari tugas pemimpin. Memotivasi orang lain berarti mengajak orang lain untuk bekerja lebih keras. Motivasi adalah tantangan utama yang sudah ada sejak lama di dalam tugas manajer (Dubrin, 2009: 12).

Gaya pemimpin motivatif ini merupakan gaya pemimpin dengan menyampaikan segala ide, program dan kebijakan kepada bawahan secara baik dan memberikan dorongan semangat kepada orang lain untuk bekerja lebih keras.

\section{Gaya Edukatif}

Gaya pemimpin edukatif adalah pemimpin yang suka melakukan pengembangan bawahan dengan cara memberikan pendidikan dan keterampilan kepada bawahan, sehingga bawahan menjadi memiliki wawasan dan pengalaman yang lebih baik dari hari ke hari, sehingga seorang pemimpin yang bergaya edukatif tidak akan pernah menghalangi 
bawahan ingin megembangkan pendidikan dan keterampilan (Sutrisno, 2010: 245).

Gaya kepemimpinan ini selalu mempercayakan kepada bawahan untuk selalu mengembangkan kependidikan dan keterampilan guna menambah wawasan dan pengalaman yang lebih baik.

Gaya-gaya kepemimpinan yang merupakan tolok ukur akan keberhasilan berjalannya suatu organisasi. Semua gaya kepemimpinan di atas dalam praktiknya di lapangan saling mendukung atau saling menunjang secara bervariasi, yang disesuaikan dengan situasi dan kondisinya sehingga akan menghasilkan kepemimpinan yang efektif.

Tabel 2. Gaya Kepemimpinan

\begin{tabular}{|c|c|c|}
\hline $\begin{array}{c}\text { Gaya } \\
\text { Kepemimpinan }\end{array}$ & Pendekatan & Bawahan \\
\hline Persuasif & $\begin{array}{l}\text { menggunakan pendekatan } \\
\text { yang menggugah perasaaan, } \\
\text { pikiran }\end{array}$ & $\begin{array}{l}\text { Pekerjaan dilaksanakan } \\
\text { atas dasar kemauan } \\
\text { sendiri }\end{array}$ \\
\hline Represif & $\begin{array}{l}\text { gaya kepemimpinan dengan } \\
\text { cara memberikan tekanan- } \\
\text { tekanan, ancaman-ancaman }\end{array}$ & $\begin{array}{l}\text { Pekerjaan dilaksanakan } \\
\text { atas dasar rasa takut }\end{array}$ \\
\hline Partisipatif & $\begin{array}{l}\text { Pemimpin menerapkan sistem } \\
\text { terbuka (open management). } \\
\text { Informasi dan pembinaan } \\
\text { kaderisasi mendapat perhatian } \\
\text { serius }\end{array}$ & $\begin{array}{l}\text { Pekerjaan dilaksanakan } \\
\text { atas dasar rasa nyaman } \\
\text { karna bekerja bersama } \\
\text { dengan pimpinan }\end{array}$ \\
\hline Inovatif & $\begin{array}{l}\text { pemimpin yang selalu } \\
\text { berusaha dengan keras untuk } \\
\text { mewujudkan usaha-usaha } \\
\text { pembaruan didalam segala } \\
\text { bidang }\end{array}$ & $\begin{array}{l}\text { Pekerjaan dilaksanakan } \\
\text { atas dasar kemauan } \\
\text { sendiri dengan upaya } \\
\text { pembaruan }\end{array}$ \\
\hline Motivatif & $\begin{array}{lr}\text { pemimpin yang } & \text { dapat } \\
\text { menyampaikan } & \text { informasi } \\
\text { mengenai } & \text { ide-idenya, } \\
\text { program-program } & \text { dan } \\
\text { kebijakan-kebijakan } & \text { kepada } \\
\text { bawahan dengan baik. } & \\
\end{array}$ & $\begin{array}{l}\text { Pekerjaan dilaksanakan } \\
\text { atas dasar kemauan } \\
\text { sendiri dengan penuh } \\
\text { semangat atas motivasi } \\
\text { dari pemimpin }\end{array}$ \\
\hline Edukatif & $\begin{array}{lr}\text { suka } & \text { melakukan } \\
\text { pengembangan } & \text { bawahan } \\
\text { dengan cara } & \text { memberikan } \\
\text { pendidikan dan keterampilan }\end{array}$ & $\begin{array}{lr}\text { Seolah } & \text { selalu } \\
\text { merasakan ada } & \text { banyak } \\
\text { pembelajaran } & \text { sebab } \\
\text { sering diikut } & \text { sertakan }\end{array}$ \\
\hline
\end{tabular}


Kaitan gaya dengan tipologi sangat berperan dalam keberhasilan sebuah organisasi, kepemimpinan yang baik harus memiliki penyesuaian baik dalam gaya yang diperlukan dalam memimpin dan tipe yang digunakan dalam menggerakan organisasi. Ketika pemimpin memilih gaya kepemimpian yang baik dan tidak di dorong dengan tipe kepemimpinan dalam interaksipersonal maka semua akan memiliki kendala dalam mencapai tujuan berorganisasi.

\section{Kesimpulan}

Suatu organisasi akan berhasil atau gagal sebagian besar ditentukan oleh kepemimpinan lembaga itu sendiri termasuk lembaga pendidikan baik sekolah maupun madrasah. Kepemimpinan yang dimiliki setiap pemimpin akan berpengaruh besar terhadap pencapaian tujuan pendidikan. Ada banyak tipe kepemimpinan yang ada dalam manajemen sebagaimana yang telah dipaparkan pada bagian sebelumnya. Tipe kepemimpinan ini juga dipengaruhi oleh gaya seseorang yang memimpin itu.

Tipe kepemimpinan adalah gaya atau corak kepemimpinan yang dibawakan oleh seorang pemimpin dalam mempengaruhi para pengikutnya. Gaya seorang pemimpin dalam menjalankan kepemimpinan dipengaruhi oleh berbagai faktor antara lain faktor pendidikan, pengalaman, usia, karakter tabiat atau sifat yang ada pada diri pemimpin tersebut. Orang yang ambisius untuk menguasai setiap situasi apabila menjadi pemimpin cenderung akan bersifat otoriter. Orang yang mempunyai sifat kebapakan apabila menjadi pemimpin cenderung akan menjalankan kepemimpinan yang bertipe paternalistik sedangkan pemimpin yang tidak menguasai bidang tugas yang menjadi wewenangnya akan menyerahkan segala sesuatunya pada bawahan sehingga gaya kepemimpinannya cenderung bersifat laissez faire.

\section{Referensi}


Afifuddin. 2005. Administrasi Pendidikan. Insan Mandiri. Bandung.

Ahmad, Tohardi. 2002. Pemahaman Praktis Manajemen Sumber Daya Manusia. CV. Mandar Maju. Jakarta.

Dubrin, Andrew J. 2009. The Complete Ideal's Guides Leadership. Prenada. Jakarta.

Depdiknas. 2008. Kamus Besar Bahasa Indonesia. Gramedia Pustaka Indonesia.

Dwiwibawa. F. Rudy dan Riyanto. 2008. Siap Jadi Pemimpin? Latihan Dasar Kepemimpinan. Kanisius. Yogyakarta.

Guritno, Bambang dan Waridin. 2005. Pengaruh Persepsi Karyawan Mengenai Perilaku Kepemimpinan, Kepuasan Kerja dan Motivasi Terhadap Kinerja. Jurnal Riset Bisnis Indonesia. 1(1): 63-74.

Hasibuan S.P Malayu. 2006. Manajemen Dasar, Pengertian dan Masalah. cetakan kelima. Bumi Aksara. Jakarta.

Hersey, 2004. Kunci Sukses Pemimpin Situasional. Delaprasata. Jakarta.

Sharma, M.K. 2013. Leadership Management: Principles, Models and Theories Global, Journal of Management and Business Studies 3(3): 309-318.

Masrukhin dan Waridin. 2006. Pengaruh Motivasi Kerja, Kepuasan Kerja, Budaya Organisasi dan Kepemimpinan terhadap Kinerja Pegawai, Jurnal Ekonomi \& Bisnis 7(2): 197-209.

Nawawi, Hadari. 2003. Kepemimpinan Mengefektifkan Organisasi. Gajah Mada University Press. Yogyakarta.

Robbins, Stephen. P. 2006. Perilaku organisasi. Edisi Bahasa Indonesia. PT Indeks Kelompok GRAMEDIA. Jakarta.

Suryosubroto. 2010. Manajemen Pendidikan di Sekolah. Rineka Cipta. Jakarta.

Sutikno, Sobri. 2009. Pengelolaan Pendidikan. Prospect. Bandung.

Sutrisno, Edy. 2010. Manajemen Sumber Daya Manusia. Kencana. Jakarta.

Tjiptono, Fandy. 2006, Manajemen Pelayanan Jasa. Penerbit Andi. Yogyakarta.

Saihu, S. (2019). RINTISAN PERADABAN PROFETIK UMAT MANUSIA MELALUI PERISTIWA TURUNNYA ADAM AS KE-DUNIA. Mumtaz: Jurnal Studi Al-Quran dan Keislaman, 3(2), 268-279,

Saihu, S. (2019). Pendidikan Pluralisme Agama: Kajian tentang Integrasi Budaya dan Agama dalam Menyelesaikan Konflik Sosial Kontemporer. Jurnal Indo-Islamika, 9(1), 67-90, 
Saihu, S. (2019). IMPLEMENTASI MANAJEMEN BALANCED SCORECARD DI PONDOK PESANTREN JAM'IYYAH ISLAMIYYAH TANGERANG SELATAN. Mumtaz: Jurnal Studi Al-Quran dan Keislaman, 3(1), 1-22.

Saihu, S. (2019). KOMUNIKASI PENDIDIK TERHADAP ANAK BERKEBUTUHAN KHUSUS DI SEKOLAH KHUSUS ASY-SYIFA LARANGAN. Andragogi: Jurnal Pendidikan Islam dan Manajemen Pendidikan Islam, 1(3), 418-440.

Saihu, S., \& Marsiti, M. (2019). PENDIDIKAN KARAKTER DALAM UPAYA MENANGKAL RADIKALISME DI SMA NEGERI 3 KOTA DEPOK, JAWA BARAT. Andragogi: Jurnal Pendidikan Islam dan Manajemen Pendidikan Islam, 1(1), 23-54.

Saihu, S. (2019). KONSEP MANUSIA DAN IMPLEMENTASINYA DALAM PERUMUSAN TUJUAN PENDIDIKAN ISLAM MENURUT MURTADHA MUTHAHHARI. Andragogi: Jurnal Pendidikan Islam dan Manajemen Pendidikan Islam, 1(2), 197-217.

Saihu, S., \& Rohman, B. (2019). PEMBENTUKAN KARAKTER MELALUI MODEL PENDIDIKAN TRANSFROMATIFE LEARNING PADA SANTRI DI PONDOK PESANTREN NURUL IKHLAS BALI. Edukasi Islami: Jurnal Pendidikan Islam, 8(02), 435-452.

Saihu, S., \& Taufik, T. (2019). PERLINDUNGAN HUKUM BAGI GURU. $A l$ Amin: Jurnal Kajian Ilmu dan Budaya Islam, 2(2), 105-116.

Saihu, S. (2020). KONSEP PEMBAHARUAN PENDIDIKAN ISLAM MENURUT FAZLURRAHMAN. Andragogi: Jurnal Pendidikan Islam dan Manajemen Pendidikan Islam, 2(1), 82-95.

Saihu, S. (2020). ETIKA MENUNTUT ILMU MENURUT KITAB TA'LIM MUTA'ALIM. Al Amin: Jurnal Kajian Ilmu dan Budaya Islam, 3(1), 99112.

Saihu, Aziz, A., Mubin, F., \& Sarnoto, A. Z. (2020). Design of islamic education based on local wisdom (An analysis of social learning theories in forming character through ngejot tradition in bali). International Journal of Advanced Science and Technology, 29(6), 1278-1293.

Ronaldo, R., Zulfikar, A., Saihu, Ismail, \& Wekke, I. S. (2020). International relations of the asia pacific in the age of trump. Journal of Environmental Treatment Techniques, 8(1), 244-246.

Saihu, M. M., \& Aziz, A. (2020). Implementasi Metode Pendidikan Pluralisme Dalam Mata Pelajaran Pendidikan Agama Islam. Belajea; Jurnal Pendidikan Islam, 5(1), 131-150.

Saihu, M. (2019). Urgensi 'Urf dalam Tradisi Male dan Relevansinya dalam Dakwah Islam di Jembrana-Bali. Jurnal Bimas Islam, 12(1), 173-201.

Saihu, S. (2020). The Effect of Using Talking Stick Learning Model on Student Learning Outcomes in Islamic Primary School of Jamiatul Khair, Ciledug Tangerang. Tarbawi: Jurnal Keilmuan Manajemen Pendidikan, 6(01), 6168.

Saihu, S. (2020). Pendidikan sosial yang terkandung dalam Surat At-Taubah Ayat 71-72. Edukasi Islami: Jurnal Pendidikan Islam, 9(01), 127-148. 
Aziz, A., \& Saihu, S. (2019). Interpretasi Humanistik Kebahasaan: Upaya Kontekstualisasi Kaidah Bahasa Arab. Arabiyatuna: Jurnal Bahasa Arab, 3(2), 299-214

Saihu, S. (2019). PENDIDIKAN KARAKTER BERBASIS KEARIFAN LOKAL (STUDI DI JEMBRANA BALI). Edukasi Islami: Jurnal Pendidikan Islam, 8(01), 69-90.

Şahin, C. RELIGIA.

Saihu, S., \& Mailana, A. (2019). Teori pendidikan behavioristik pembentukan karakter masyarakat muslim dalam tradisi Ngejot di Bali. Ta'dibuna: Jurnal Pendidikan Islam, 8(2), 163-176.

Mubin, F. KEADILAN DALAM GENDER: KAJIAN KEPEMIMPINAN WANITA DALAM ISLAM1,

Saihu, M. (2019). Merawat Pluralisme Merawat Indonesia (Potret Pendidikan Pluralisme Agama Di Jembrana-Bali). Deepublish.

Mubin, F. (2019). TAFSIR EMANSIPATORIS: PEMBUMIAN METODOLOGI TAFSIR PEMBEBASAN. Mumtaz: Jurnal Studi Al-Quran dan Keislaman, 3(1), 131-151.

Mubin, F. MODEL-MODEL PEMBELAJARAN BERBASIS MADRASAH DAN KEGIATAN LAIN YANG DIPERLUKAN DI DALAMNYA (FAKTOR PENDUKUNGNYA).

Saihu, S. (2018). PENDIDIKAN ISLAM MULTIKULTURALISME. Al Amin: Jurnal Kajian Ilmu dan Budaya Islam, 1(2), 170-187. 